\title{
Commentary: Cats prefer species-appropriate music
}

\author{
Cinzia Chiandetti * \\ Department of Life Sciences, University of Trieste, Trieste, Italy
}

Keywords: consonance, biomusicology, core knowledge, acoustic brick, animate categorization

\section{A commentary on}

Cats prefer species-appropriate music

by Snowdon, C. T., Teie, D., and Savage, M. (2015). Appl. Anim. Behav. Sci. 166, 106-111. doi: 10.1016/j.applanim.2015.02.012

Whether or not other animal species can appreciate human music is an issue that intrigues thinkers, scientists and artists (as well as pet owners). Yet, to date, despite a rather conspicuous corpus of studies using different investigating strategies with different animal species, no univocal answer does exist. There is contrasting evidence on the effects of music listening on animals' physiology and behavior [for a review Alworth and Buerkle (2013)] and ambiguous results on their appreciation of musical genres. To animals' ears, sometimes silence appears to be more pleasurable than human music (McDermott and Hauser, 2007; Mingle et al., 2014).

At a closer look, the initial question can be reduced to a more substantial one: Why should non-human animals respond to human music? With this query in mind, Snowdon and colleagues composed ad hoc music to elicit congruent emotions in cats (Snowdon et al., 2015) and, previously, in cotton-top tamarins (Snowdon and Teie, 2010). By considering ecological and sensorial differences between species, the authors composed music starting from feats of species-specific vocalizations and animals responded to it by emitting emotionally congruent responses. Also, animals' manifestations were stronger and occurred within a shorter delay from the onset of the species-specific musical pieces than when human music was played, thus apparently proving that species-specific music is a far more relevant stimulus for them.

In all musical pieces, Snowdon and colleagues included basic musical feats as modo (major or minor), articulation (legato or staccato) and structure (consonant or dissonant). These feats are universal acoustic bricks that composers regularly use to induce specific feelings in the listeners (Bresin and Friberg, 2011), and that surmount to local variations due to cultural differences (Balkwill and Thompson, 1999).

Such universal acoustic bricks are also recognizable in prosody and similarly affect both human newborns of distant linguistic areas and domesticated animals (Fernald, 1992). Dogs and horses, for instance, respond congruently to verbal commands (McConnnell, 1990) as human infants do, something that has proved to be unrelated to exposure, hence conditioning.

Among these universals, the consonant intervals or structures are as essential as debated. Indeed, on the specific valence of consonant sounds, the results are far from being clear. There are studies showing a preference for this type of sounds in the infants of our species (Zentner and Kagan, 1998), a baby chimp (Sugimoto et al., 2010), and newly-hatched chicks (Chiandetti and Vallortigara, 2011a). Our brain seems to be hard-wired at birth for the appreciation of harmonic tones 
(Perani et al., 2010), and the babies of deaf people show signs of appreciation as well (Masataka, 2006). There are also studies revisiting the preference in infants (Plantinga and Trehub, 2014) or showing no preference for consonance in monkeys (cotton-top tamarins: McDermott and Hauser, 2004; Campbell's monkeys: Koda et al., 2013). However, note that no research has ever found the opposite pattern of results, i.e., a significant preference for the dissonant version of the stimuli used.

Consonant harmonies were comprised in the calming music composed for cats by Snowdon and colleagues. Hence, such a melodic relation between frequencies is typical in cats' calls, just as it is in general in vocalizations (Schwartz et al., 2003). There are striking examples of consonant intervals in the songs of some species of birds (musician wren: Doolittle and Brumm, 2013; hermit thrush: Doolittle et al., 2014), frogs (Akre et al., 2014), and beyond suspicion mosquitoes that, during their love songs, converge in a harmonic matching (Cator et al., 2009). Furthermore, during a conversation, whenever interlocutors agree, the tonics of the phrasing become consonant (Okada et al., 2012).

Hence, harmonics are naturally present in animals' communication and may well serve to calm species universally, being crucial in affiliative interactions. Then, from the perspective in which consonant harmonies likely represent a pervasive and phylogenetically ancient brick, the question of whether other animal species prefer consonances is a well-posed one. Indeed, a general interest for consonance could be expected in virtue of its ancestral and simple biological function (Bowling and Purves, 2015), which might have been that of an indicator to discriminate animate from inanimate objects (i.e., companions and other animals as distinct from other natural sounds).

A musical feat such as consonance, together with other basic components and related acoustic mechanisms to appreciate them, could complement well-known mechanisms absolving the same purpose in a different sensorial modality: the visual domain. Newborns can visually reason about the basic physical properties of inanimate objects (Baillargeon, 1994) and discriminate objects from agents with internal motivations (Luo and Baillargeon,

\section{REFERENCES}

Akre, K. L., Bernal, X., Rand, A. S., and Ryan, M. J. (2014). Harmonic calls and indifferent females: no preference for human consonance in an anuran Harmonic calls and indifferent females: no preference for human consonance in an anuran. Proc. R. Soc. B Biol. Sci. 281, 20140986. doi: 10.1098/rspb.2014.0986

Alworth, L. C., and Buerkle, S. C. (2013). The effects of music on animal physiology, behavior and welfare. Lab. Anim. 42, 54-61. doi: 10.1038/laban.162

Baillargeon, R. (1994). How do infants learn about the physical world? Curr. Dir. Psychol. Sci. 3, 133-140. doi: 10.1111/1467-8721.ep10770614

Balkwill, L., and Thompson, W. F. (1999). A cross-cultural investigation of the perception of and cultural cues emotion in music: psychophysical and cultural cues. Music. Percept. Interdiscip. J. 17, 43-64.

Bowling, D. L., and Purves, D. (2015). A biological rationale for musical consonance. Proc. Natl. Acad. Sci. U.S.A. 112, 11155-11160. doi: 10.1073/pnas.1505768112

Bresin, R., and Friberg, A. (2011). Emotion rendering in music: range and characteristic values of seven musical variables. Cortex 47, 1068-1081. doi: 10.1016/j.cortex.2011.05.009

Carey, S. (2009). The Origin of Concepts. Oxford: Oxford University Press.
2005). Even a precocial species such as the domestic chick represents a world with specific physical (Chiandetti and Vallortigara, 2011b) and psychological laws (Mascalzoni et al., 2010) on the basis of visual characteristics. Several studies now support a Kantian view of the origin of knowledge, posing that a limited set of core knowledge would have been molded by evolution through natural selection and would be endowed in our brains to serve as the basis of our reasoning about physical and social objects, as well as space and number (Spelke, 2000; Carey, 2009; Vallortigara, 2012). This set of core knowledge seems to be largely shared across species (Vallortigara et al., 2010). Along with invariant visual mechanisms, evolution could have shaped acoustic mechanisms to appreciate universal acoustic bricks with the aim of identifying other organisms.

Snowdon et al. (2015) have the merit of having stressed the relevance of the analysis of species-specific sensory signatures to elicit animals' emotional response. However, they based the compositions on universally efficacious musical principles, among which consonance is an example, and that made the pieces attractive for human listeners, too. Cats preferred the melody created for them, but humans liked the music composed for cats. In this sense, their results confirm that there is preference for "musical sounds" in animals, but only limitedly to the interest for features in virtue of their more broad biological and social importance.

Such bricks, typical of living entities, could represent the innate precursor at the basis of the blooming of further musical abilities.

\section{AUTHOR CONTRIBUTIONS}

The author confirms being the sole contributor of this work and approved it for publication.

\section{FUNDING}

This work was partially supported by a UniTs-FRA2015 grant.

Cator, L. J., Arthur, B. J., Harrington, L. C., and Hoy, R. R. (2009). Harmonic convergence in the love songs of the dengue vector mosquito. Science 323, 1077-1079. doi: 10.1126/science.1166541

Chiandetti, C., and Vallortigara, G. (2011a). Chicks like consonant music. Psychol. Sci. 22, 1270-1273. doi: 10.1177/0956797611418244

Chiandetti, C., and Vallortigara, G. (2011b). Intuitive physical reasoning about occluded objects by inexperienced chicks. Proc. R. Soc. B Biol. Sci. 278, 2621-2627. doi: 10.1098/rspb.2010.2381

Doolittle, E. L., and Brumm, H. (2013). O Canto do Uirapuru: consonant intervals and patterns in the song of the musician wren. J. Interdiscip. Music Stud. 6, 55-85. doi: 10.4407/jims.2013.10.003

Doolittle, E. L., Gingras, B., Endres, D. M., and Fitch, W. T. (2014). Overtonebased pitch selection in hermit thrush song: unexpected convergence with scale construction in human music. Proc. Natl. Acad. Sci. U.S.A. 111, 16616-16621. doi: 10.1073/pnas.1406023111

Fernald, A. (1992). "Human maternal vocalizations to infants as biologically relevant signals: an evolutionary perspective," in The Adapted Mind: Evolutionary Psychology and the Generation of Culture, eds J. Barkow, L. Cosmides, and J. Tooby (New York, NY: Oxford University Press), $391-428$ 
Koda, H., Basile, M., Olivier, M., Remeuf, K., Nagumo, S., Basile, M., et al. (2013). Validation of an auditory sensory reinforcement paradigm: campbell' s monkeys (Cercopithecus campbelli) do not prefer consonant over dissonant sounds. J. Comp. Psychol. 127, 265-271. doi: 10.1037/a0031237

Luo, Y., and Baillargeon, R. (2005). Can a self-propelled box have a goal? Psychological reasoning in 5-month-old infants. Psychol. Sci. 16, 601-608. doi: $10.1111 /$ j.1467-9280.2005.01582.x

Masataka, N. (2006). Preference for consonance over dissonance by hearing newborns of deaf parents and of hearing parents. Dev. Sci. 9, 46-50. doi: 10.1111/j.1467-7687.2005.00462.x

Mascalzoni, E., Regolin, L., and Vallortigara, G. (2010). Innate sensitivity for selfpropelled causal agency in newly hatched chicks. Proc. Natl. Acad. Sci. U.S.A. 107, 4483-4485. doi: 10.1073/pnas.0908792107

McConnnell, P. (1990). Acoustic structure and receiver response in domestic dogs (Canis familiaris). Anim. Behav. 39, 897-904. doi: 10.1016/S00033472(05)80954-6

McDermott, J., and Hauser, M. (2004). Are consonant intervals music to their ears? Spontaneous acoustic preferences in a nonhuman primate. Cognition 94, 11-21. doi: 10.1016/j.cognition.2004.04.004

McDermott, J., and Hauser, M. D. (2007). Nonhuman primates prefer slow tempos but dislike music overall. Cognition 104, 654-668. doi: 10.1016/j.cognition.2006.07.011

Mingle, M. E., Eppley, T. M., Campbell, M. W., Hall, K., Horner, V., Waal, De., et al. (2014). Chimpanzees prefer african and indian music over silence. J. Exp. Psychol. Anim. Learn. Cogn. 40, 502-505. doi: 10.1037/xan0000032

Okada, B. M., Lachs, L., and Boone, B. (2012). Interpreting tone of voice: musical pitch relationships convey agreement in dyadic conversation. J. Acoust. Soc. Am. 132, 208-214. doi: 10.1121/1.4742316

Perani, D., Cristina, M., Scifo, P., Spada, D., Andreolli, G., and Rovelli, R. (2010). Functional specializations for music processing in the human newborn brain. Proc. Natl. Acad. Sci. U.S.A. 107, 4758-4763. doi: 10.1073/pnas.0909074107

Plantinga, J., and Trehub, S. E. (2014). Revisiting the innate preference for Consonance. J. Exp. Psychol. Hum. Percept. Performance 40, 40-49. doi: 10.1037/a0033471
Schwartz, D. A., Howe, C. Q., and Purves, D. (2003). The statistical structure of human speech sounds predicts musical universals. J. Neurosci. 23, $7160-7168$.

Snowdon, C. T., and Teie, D. (2010). Affective responses in tamarins elicited by species-specific music. Biol. Lett. 6, 30-32. doi: 10.1098/rsbl.20 09.0593

Snowdon, C. T., Teie, D., and Savage, M. (2015). Cats prefer speciesappropriate music. Appl. Anim. Behav. Sci. 166, 106-111. doi: 10.1016/j.applanim.2015.02.012

Spelke, E. (2000). Core knowledge. Am. Psychol. 55, 1233-1243. doi: 10.1037/0003066X.55.11.1233

Sugimoto, T., Kobayashi, H., Nobuyoshi, N., Kiriyama, Y., Takeshita, H., Nakamura, T., et al. (2010). Preference for consonant music over dissonant music by an infant chimpanzee. Primates 51, 7-12. doi: 10.1007/s10329-0090160-3

Vallortigara, G. (2012). Core knowledge of object, number, and geometry: a comparative and neural approach. Cogn. Neuropsychol. 29, 213-236. doi: $10.1080 / 02643294.2012 .654772$

Vallortigara, G., Chiandetti, C., Rugani, R., Sovrano, V. A., and Regolin, L. (2010). Animal cognition. Wiley Interdiscip. Rev. Cogn. Sci. 1, 882-893. doi: $10.1002 /$ wcs. 75

Zentner, M. R., and Kagan, J. (1998). Infants' perception of consonance dissonance in music and. Infant 21, 483-492.

Conflict of Interest Statement: The author declares that the research was conducted in the absence of any commercial or financial relationships that could be construed as a potential conflict of interest.

Copyright $\odot 2016$ Chiandetti. This is an open-access article distributed under the terms of the Creative Commons Attribution License (CC BY). The use, distribution or reproduction in other forums is permitted, provided the original author(s) or licensor are credited and that the original publication in this journal is cited, in accordance with accepted academic practice. No use, distribution or reproduction is permitted which does not comply with these terms. 